\title{
Whitehead’s Categoreal Scheme as a Social-Psychiatric Game-Autism and Metaphysics
}

\author{
Lehel Simon, Levente Szilágyi, Anna Csetverikov \\ Entactex Pharma Research Project
}

\begin{abstract}
The lack of emotional relations is not replaced by the "savant” characteristics (see Asperger syndrome) but by their immersing into stereotypic instincts. In other words, they compensate their divergent intrinsic emotions with imitated convergences (eg., the monotonous “convergence obsessed” logic of hammering, wringing hands etc.) Today's science cannot declare this to be convergent, especially for the fact that psychotic autist patients prove to be weak at convergence, but the male/female proportion reflects on notable facts (with Kanner syndrome it is 3:1 or 4:1, while Rett syndrome only affects females). Can we declare Kanner and Rett syndromes to be basically female brain disorders? Asperger-autism has been scientifically considered as a type of "male-brain disorder” since 1991 (Baron-Cohen theory). The proportion of male-female is approximately 6:1 with this disease. The author would like to demonstrate a very special case, the Asperger-autism as a "cognitive autism.” It is common to address autistic disorder as "pervasive” or "comprehensive" ontogenetic disorders because they affect all areas of adolescent psychological development negatively. But as the expression itself suggests, we are not aware of the specific disorders directly. As it will turn out we cannot deal with autism as on complex disorder, we should rather use the term in plural, i.e., autisms and autistic disorders.
\end{abstract}

Keywords: psychology, philosophy of mind, Autism, gender studies, social psychiatry

\section{Introduction}

The question has been put into focus recently: Is the Whiteheadian process ${ }^{1}$ reproducible, e.g., in a hermeneutic situation?

The hermeneutic situation is narrative but the process from Whitehead is universal. Our scientific plan is to involve the narrative repetition into universal categories. This will catalyze the Whiteheadian universal process to overcome its philosophical generality so that it becomes in itself a process experienced completely by the self. My aim is to portray the spontaneity of the psychodrama and the metaphysical constant of the Whiteheadian process into one complete system—at the same time lived and observed—and in the end not to just solve the metaphysical but also the psychological understanding of the superject. ${ }^{2}$

In other words, are actors of a debate capable of producing the same reality?

Lehel Simon, MA, Independent Researcher, Hungary; main research fields: Philosophy, Clinical Psychology, and Psychiatry. Email: lehel.alpar@gmail.com.

Levente Szilágyi, MA, Independent Researcher, Hungary; main research fields: Cultural Anthropology, History of Art, and Linguistics. Email: leves.leves@gmail.com.

Anna Csetverikov, MA, Independent Researcher, Hungary; main research field: Psychology of Language. Email: anna.csetverikov@gmail.com.

This research is sponsored by MOHA Foundation (Hungarian foundation supporting residential homes for autistic people). 
The spontaneity is at the same time constant and changing: If we are able to act out the Whiteheadian universality of the process whilst seeing ourselves from above, then there is no contradiction between the happening and the experiencing of the process. This is how the Whiteheadian metaphysic will become a self-experience in its ordinary "vulgarity;" but not in a philosophical way anymore, but as a tool of scientific psychotherapy. Because if I confront the patient with a part of itself that can't be seen in the superject but is actually him/her, than the practice of the experience of the universal self will under-or overcome all the games between the subject and the superject.

The actors' integrity of subject and superject is unified, which includes the superior and the concrete forms of being from dramatic areas to "vulgar" life processes. We represent through the article psychodramatic psychoanalysis in phenomenon of Asperger-autism. The autism is a metaphor of our acting out in our personal life, but not only in our subject, also in our "actual superject," as the aspergerian autists can view the world and themselves from their universal superiority. This represents the possibility to create contemporary psychological (namely psychodramatic, heterodox psychoanalytical, and cognitive psychological) methods, the theoretical completion of which will take more time.

If the duality of the superject-subject game can be resolved and understood in a spontaneous psychodramatic experience, than the Whiteheadian constant will complete the Morenoian spontaneity. ${ }^{3}$ By this way, Whitehead will submit as psychology, and maybe 16 years after Moreno we can create the metaphysical theory of the psychodrama. These are the mutual benefits of the synergies between psychology and philosophies. The upper context dissolves the actual difference between events and spontaneity; the actor is the human being, and the human being is the eternal actor without drama: This is the "spontan process reality"-eternal and real. In our research, we have rendered the philosophical process of the Whiteheadian superject-subject relation phenomenon into a special dramatical language-game, which may provide a model for the scientific understanding of the - theoretically to this day unborn—narrative concepts of the post-modern period: language-game as a "science of reality," that is to say, psychological practice. We would like to introduce a language-game in the following: the dramatic appearance of the process and the reality in the superject.

The conclusion of this language-game is that the subject playing with the real process metaphysically defines the superject-this is the natural human condition. The honest revelation of the superject however excludes the above position. Thus the post-modern science gains a particular position: It realizes the disappearance of the metaphysics in the new process 80 years after Whitehead. This recognition itself creates the metaphysics - the question goes and still the question remains. In our psychological-philosophical game, the superject is the psychiatry, but we are the subjects like autistic children in process: This is a social-psychiatric "liberator" game for the really ill children in "reality."

In our paper, we would like to manifest the discourse of a Whiteheadian approach in practical clinical psychology, especially in psychotherapy of Asperger-autism. We wish to dedicate our work for Whiteheadian interpretation of this narrative science.

\section{Discussion}

It is common to address autistic disorder as "pervasive" or "comprehensive" ontogenetic disorders because they affect all areas of adolescent psychological development negatively. But as the expression itself suggests, the truth is that we are not directly aware of the specific disorders. As it will turn out that we cannot deal with 
autism as a complex disorder, we should rather use the term in plural i.e., autisms and autistic disorders. ${ }^{4}$

In my lecture, I would like to point out the Asperger syndrome, because this autistic personality disorder has a so-called "acting out" between the process of "subject superior" (in Whiteheadian philosophy it's the "superject" ${ }^{5}$ ), and that of the "subject interior" which means the personality's reality in the human psychological integrity. The superject dominates the person who has a schisis between its social and the own personal integrity. The individual psychological processes are under the superior reality. But the superior reality is the patient's stronger psychical entity above the own personality. Reality versus psychological continuity—psychodynamic process contra social reality—metaphysical supremacy contra psychical process of the emotional interiorization: "out” inside of the own personality, but not "out” from personality. "Psychopathy, not psychosis” as was said by Hans Asperger immigrants Austrian psychiatrist and pediatrician. But we haven’t really got a psychoanalytical model for this syndrome, so we cannot make analytical therapy for an analytical intellectual disorder form.

The Asperger Syndrome (AS) has been in use as a diagnostic criterion since 1944; it was called then “Autistic psychopathy.” It only got the name Asperger syndrome referring to the first diagnostician from Lorna Wing psychologist and her psychoanalyst colleagues in 1981. After all, it was only involved in the official system of DSM-IV ${ }^{6}$ as a unique syndrome in 1994 and it is still much debated etiologically and from other aspects.

It is interesting and its importance will be emphasized later that the male versus female occurrence rate is $6: 1{ }^{7}$ and it does not show symptoms in early childhood while other autisms do so. Its real occurrence is frequently met after the age of six. Even today it is considered by clinical child psychologists as a child psychopathy and no etiologic relation is seen between psychotic and neurodegenerative autisms. The fact that the IQ of children with AS is usually outstandingly high —often exceeds the value 140-provides further support of this idea. We are going to point out that the classification spread in the 90s was totally wrong by saying that this is a mild form of autisms ${ }^{8}$ as opposed to the seriously retarded Kanner's syndrome which was considered as a severe form of autism in this old classification. After 1994 we cannot even talk about such a division.

\section{Psychological Models}

It is much debated whether it exclusively hits boys. There are many arguments which say that we tend to pay more attention to boy gender samples, ${ }^{9}$ especially when they show extreme intellectual capacity. Though the above mentioned prevalence rate is generally accepted, it is unquestionable as for the contemporary statistical data. Its frequency is $2 / 10000$ (though as we know the prevalence of every autistic clinical aspect has dramatically grown in the last 20 years, these are also official data from 1995 further on). ${ }^{10}$

If we take a look at the latest psychological function theory of AS (Baron-Cohen EQ-SQ theory), ${ }^{11}$ the male-female rate proves even more to be right, functionally too. This is because besides the extremely low EQ and extremely high IQ and SQ, AS strengthens the convergent comprehensive function so it results in a high organizational intelligence and in a lower emotional intelligence adversely. So the convergent male-hemisphere function is extremely dominant and the divergent feminine functions are not only incapable of communication with the convergent functions, but they are behind. ${ }^{12}$

If we look at the model described above from the aspect of psychodynamics including emotionality, it seems to be easy to establish a psychoactive model for a psychopathic scission between the systematic and 
unsystematic cognitive, emotional and personality-structure-functions. This gives a good example for the more and more accepted model which says that children with AS are likely to become adolescents or adults who produce borderline symptoms. ${ }^{13}$ We do not yet hold credible statistical data about this, but more and more psychodynamic systems state that there is successive relation between childhood psychopathy with AS and adulthood psychopathic pathographies especially borderline syndrome. ${ }^{14}$ It would be a mistake though to apply the so called "minified adult model;" AS is a unique pathography of psychopathy. ${ }^{15}$

\section{Our Psychoanalitic Therapeutical Possibility}

This is the sort of diagnostics having numerous psychoanalytic moments and the possibility of a complex Ferenczian approach built on it. The disorder does have a psychoanalytic history too, but its psychoanalytic approach in terms of therapy is a real scientific vacuum.

Since the making of the Baron-Cohen theory (1991), ${ }^{16}$ AS is considered as a "male brain disorder" thus an excessive male hemisphere function (the boy:girl rate is 6:1). In a quite curious way, the SQ and the IQ are often extremely high with people suffering the syndrome while their EQ is somewhat lower or very low (AS is also measured by SQ-EQ relative tests ${ }^{17}$ ). It is also known that convergent functions extremely dominate divergent functions. Our psychoanalytic hypothesis puts up the question of whether the convergence can be described in this case as a rational ego—self ideal—superego function (we must not forget that the disorder is the most intensive between ages six and ten with boys thus in the latency period and it debuts in the age of six, sic) and describe the lack of divergence by that "Thalassa-function" ${ }^{, 18}$ from which the "good boy" idealization segregates children.

If this is possible - though it is only a theoretic experiment yet-it would provide a chance for a mutual Ferenczian psychotherapy in the case of a pathography which has been described by psychoanalysts but has never been treated psychoanalytically.

The game is over-the game begins, but out of the walls of high secure psychiatrical clinics: in a social-psychiatrical context from child to child; into the game of integrated subject-superject and not only in process of reality, but also in reality of process; from in to out and from out to in: into anthropological integrity of a little child - in therapeutical practice. The metaphysical approach is a way for psychodramatic psychoanalysis to create the foundation for its own theory from metaphysics. The metaphysical discourse will be based scientifically without borders between psychology and metaphysics.

\section{Notes}

1. Alfred North Whitehead, "Process and Reality (Corrected Edition)." Free Press|ISBN 0029345804|Corrected Edition|1978|DJVU|398 pages|Gifford Lectures delivered at the University of Edinburgh during the session 1927-28. Corrected Edition edited by David Ray Griffin and Donald Sherburne, 50-120.

2. Whitehead's category of the philosophical entity above the subject.

3. Adam, Blatner: "History, Theory and Practice,” Springer Publishing Company, 2000, New York, 20-31.

4. Nelson: Nelson textbook of pediatrics/editor, Richard Behrman; Robert Kliegman, Valdo Nelson, Victor Vaughan, Harcourt Brace \& Company, Philadelphia, 2002 (First Hungarian Edition, 1995. Budapest, Melánia Kiadó, 72-73).

The Merck Manual—Diagnosis and Therapy (MSD Orvosi Kézikönyv Diagnózis és terápia); Editor in Chief: Robert Berkow, M. D ( Melánia Kiadó, Budapest 1994), 2267-8.

5. Alfred North Whitehead, "Process and Reality (Corrected Edition)." Free Press|ISBN 0029345804|Corrected Edition|1978|DJVU|398 page |Gifford Lectures delivered at the University of Edinburgh during the session 1927-28.

Corrected Edition edited by David Ray Griffin and Donald W. Sherburne.; pp.50-120. 
6. DSM-IV. Textrevision ( Animula Kiadó, Budapest, 1999), 41-69.

7. Wing, L. (1981), “Sex Ratios in Early Childhood Autism and Related Conditions.” Psychiatry Research, 5, 129-37.

8. DSM ibid.

9. Source: <http://www.aspergerfoundation.org.uk/infosheets/ta_girls.pdf>. "The Pattern of Abilities and Development of Girls with Asperger’s Syndrome,” Sept. 1999.

10. Nelson ibid.

11. This paper appeared in Tager Flusberg, H, (ed) Neurodevelopmental Disorders MIT Press, 1999. The extreme-male-brain theory of autism; Simon Baron-Cohen; Depertments of Experimental Psychology and Psychiatry, University of Cambridge.

12. Ibid.

13. Infant Pain Management: A Developmental Neurobiological Approach. Fitzgerald M, Walker S. M. Nat Clin Pract Neurol. 2009 Jan; 5 (1):35-50. PMID: 19129789 (PubMed - in process).

$<$ http://www.ncbi.nlm.nih.gov/pubmed/23962420>. Otto F. Kernberg: Borderline Conditions and Pathological Narcissism, Jason Aronson Inc., New York, 1957, 7-47.

14. Ibid.

15. DSM ibid.

16. The Autistic Child's Theory of Mind: A Case of Specific Developmental Delay. Baron-Cohen, Simon Journal of Child Psychology and Psychiatry 30.2 (1989): 285-97.

17. Ibid.

18. Thalassa: A Theory of Genitality, Publisher: Karnac Books; 25-36. Published: 1989. ISBN 10: 9780946439614.

\section{Works Cited}

Alfred, North Whitehead. "Process and Reality (Corrected Edition).” New York: Free Press, 1978.

Baron-Cohen, Simon. "The Autistic Child's Theory of Mind: A Case of Specific Developmental Delay.” Journal of Child Psychology and Psychiatry 30.2 (1989): 285-97.

Ferenczi Sandor. Thalassa: A Theory of Genitality. London: Karnac Books Adam, 1989.

---. “Blatner: History, Theory and Practice.” New York: Springer Publishing Company, 2000. 20-31.

Richard, Behrman, Robert Kliegman, Valdo Nelson, and Victor Vaughan. Nelson: Nelson Textbook of Pediatrics/Editor. Philadelphia: Harcourt Brace \& Company, 2002 (First Hungarian Edition, 1995. Budapest, Melánia Kiadó).

Robert, Berkow. The Merck Manual—Diagnosis and Therapy (MSD ORVOSI KÉZIKÖNYV Diagnózis és terápia). Budapest: MELANIA Kiadó Kft., 1994.

Tager, Flusberg. "The Pattern of Abilities and Development of Girls with Asperger's Syndrome.” Philadelphia: Neurodevelopmental Disorders MIT Press, 1999. 9-10.

Wing, L. Sex Ratios in Early Childhood Autism and Related Conditions. Psychiatry Research, 5, 1981.

$<$ http://www.aspergerfoundation.org.uk/infosheets/ta_girls.pdf>.

$<$ http://www.aspergerfoundation.org.uk/infosheets/ta_girls.pdf $>$.

$<$ http://www.ncbi.nlm.nih.gov/pubmed/23962420>. 